\title{
Pandemic plan: Is the vaccine supply secure?
}

Health Canada's 448-page Canadian Pandemic Influenza Plan $\vec{\sim}$ was hailed by the World Health Organization as the world's most comprehensive, but questions remain about one cornerstone of the plan: a stable vaccine supply.

The federal government has contracted Shire Biologics, a UK-based company with facili-

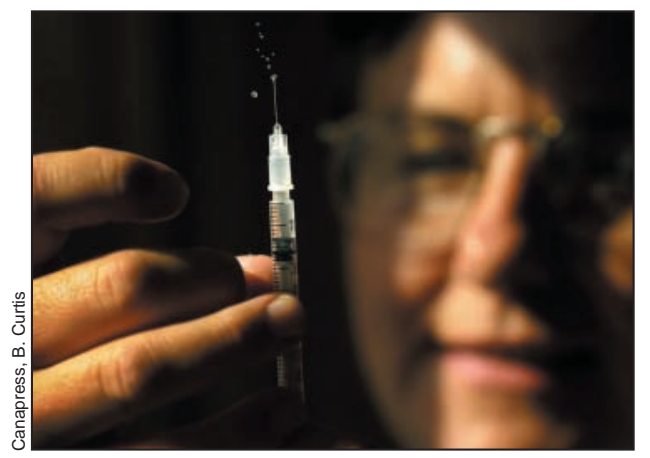

Enough vaccine for all: Shire Biologics hopes to "assure a state of readiness." ties in Laval and Sainte-Foy, Quebec, to provide pandemic influenza vaccine. However, the company is losing money $\$ 14.5$ million in the first six months of 2003 - and its parent, Shire Pharmaceuticals Group plc announced last July that it plans to sell the division this year, to focus on manufacturing pharmaceuticals.

Shire Biologics spokesperson Michèle Roy said that the sale "won't affect the contract with the Canadian government. It's a business with great potential, it's just not in the strategic focus of Shire. As an independent company it could fulfill its full potential."

In October 2001, Shire Biologics signed a \$300-million, 10year contract with the federal government to "assure a state of readiness in the case of an influenza pandemic" and to provide "a substantial portion" (75\% in 2003) of the usual annual flu vaccine. Company spokesperson Roy would not say how much money is allocated for pandemic preparedness, but the company is spending \$73 million on vaccine manufacturing and research facilities in Quebec. Canada is the first country to have a "secure vaccine supply" from a domestic source.

The plan is garnering support across Canada. Dr. Danuta Skowronski, an epidemiologist at the British Columbia Centre for Disease Control, said it provides a clear framework for dealing with an influenza outbreak. It establishes the lines of authority and brings together key players. "You have to hope for the best and prepare for the worst," she said. "We have the mechanism in place to prepare for the worst." - Ben Hadaway, CMAJ

Medical Publishing

\section{Spanish journal wins lawsuit over COX-2 drug editorial}

The debate about the safety of cyclo-oxygenase 2 (COX-2) selective inhibitor drugs reignited in February when a Spanish court rejected a lawsuit brought by the pharmaceutical company Merck, Sharpe \& Dohme (MSD) against the editor and publisher of Spain's independent drug bulletin, Butlletí Groc.

The company sued over a July 2002 article entitled "The so-called advantages of celecoxib and rofecoxib: scientific fraud." The article drew on previously published commentaries in $B M 7$ (2002;324:1287-8) and The Lancet (2002;360:100-1), which slammed the organization 을 and interpretation of 2 pivotal $\vec{q}$ studies on the safety of rofecoxib (Vioxx) and celecoxib (Celebrex) in comparison with nonselective nonsteroidal antiinflammatory drugs (NSAIDs).

Articles describing those studies — the Celecoxib Long-term
Arthritis Safety Study (CLASS) (7AMA 2000;284:1247-55) and the Vioxx Gastrointestinal Outcomes Research (VIGOR) trial (N Engl 7 Med 2000;343:1520-8) - were partly responsible for these drugs achieving phenomenal sales growth.

The manufacturer of rofecoxib used Spain's laws on "rectification" to ask the bulletin to print a retraction it had drafted. When the bulletin's publisher, the Catalan Institute of Pharmacology, refused, the company took legal action. In February, the Madrid court rejected this demand and ordered MSD to pay court costs.

Editor Joan-Ramon Laporte called MSD's retraction "mere propaganda" and said he is still concerned that both drugs are frequently prescribed inappropriately. He says that a metaanalysis of the CLASS and VIGOR trials, published in CMA7 (2002;167[10]:1131-7), shows an increased incidence of serious adverse events with these drugs compared with NSAIDs.

Peter Juni, author of the original BMf editorial, supports Laporte's editorial stance.

The bulletin's case drew messages of support from more than 700 physicians in 36 countries, as well as from the World Health Organization and the International Society of Drug Bulletins.

A spokeswoman from MSD refused to comment on whether it will pursue legal action. In a letter to $B M \mathcal{F}$ the company stated that Butlleti Groc's criticisms of the VIGOR study were based almost entirely on The Lancet commentary published in 2002 (360:100-1), which it says carried several inaccuracies. The company also says those inaccuracies were identified in a letter sent to The Lancet's editor, but this was not published. - Colin Meek, Wester Ross, Scotland 